\title{
Modelling and Shielding Analysis of the Neutral Beam Injector Ports in ITER
}

\section{P. Pereslavtsev, U. Fischer, M. Loughlin*, Lei Lu, E. Polunovskiy*, S. Vielhaber}

\section{Objective}

Inclusion new model of the NBI ports must be included in the available $80^{\circ} \mathrm{MCNP}$ model of ITER NBI sector. The following nuclear responses must be provided:

- Nuclear heating distribution in the vacuum vessel

- Nuclear heating in all ducts

- Nuclear heating and total doses to TFC magnets

- He-production and DPA distributions in VV

- Biological shutdown dose rates inside cryostat out of $V V$

\section{Simplification of the original CAD models}
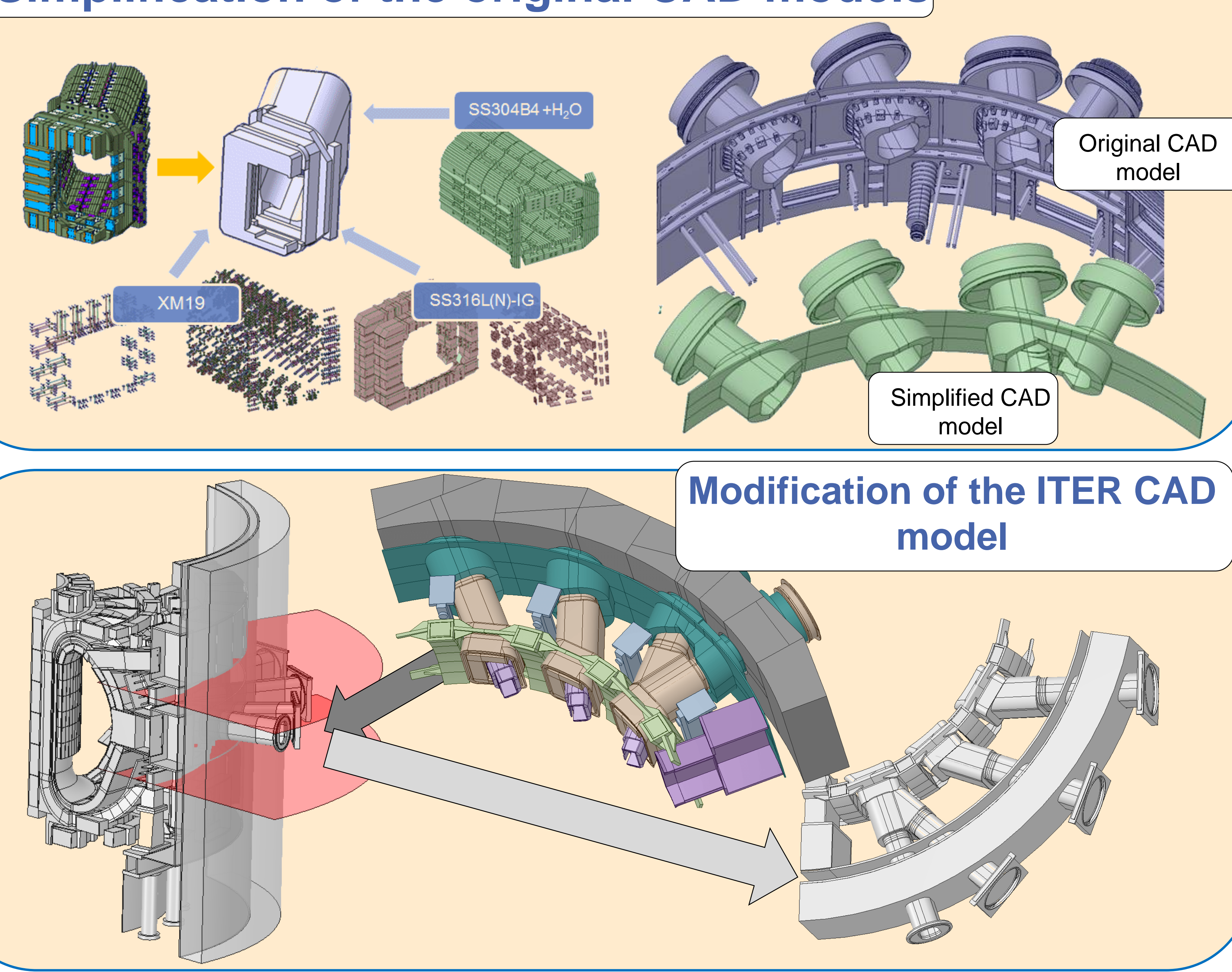
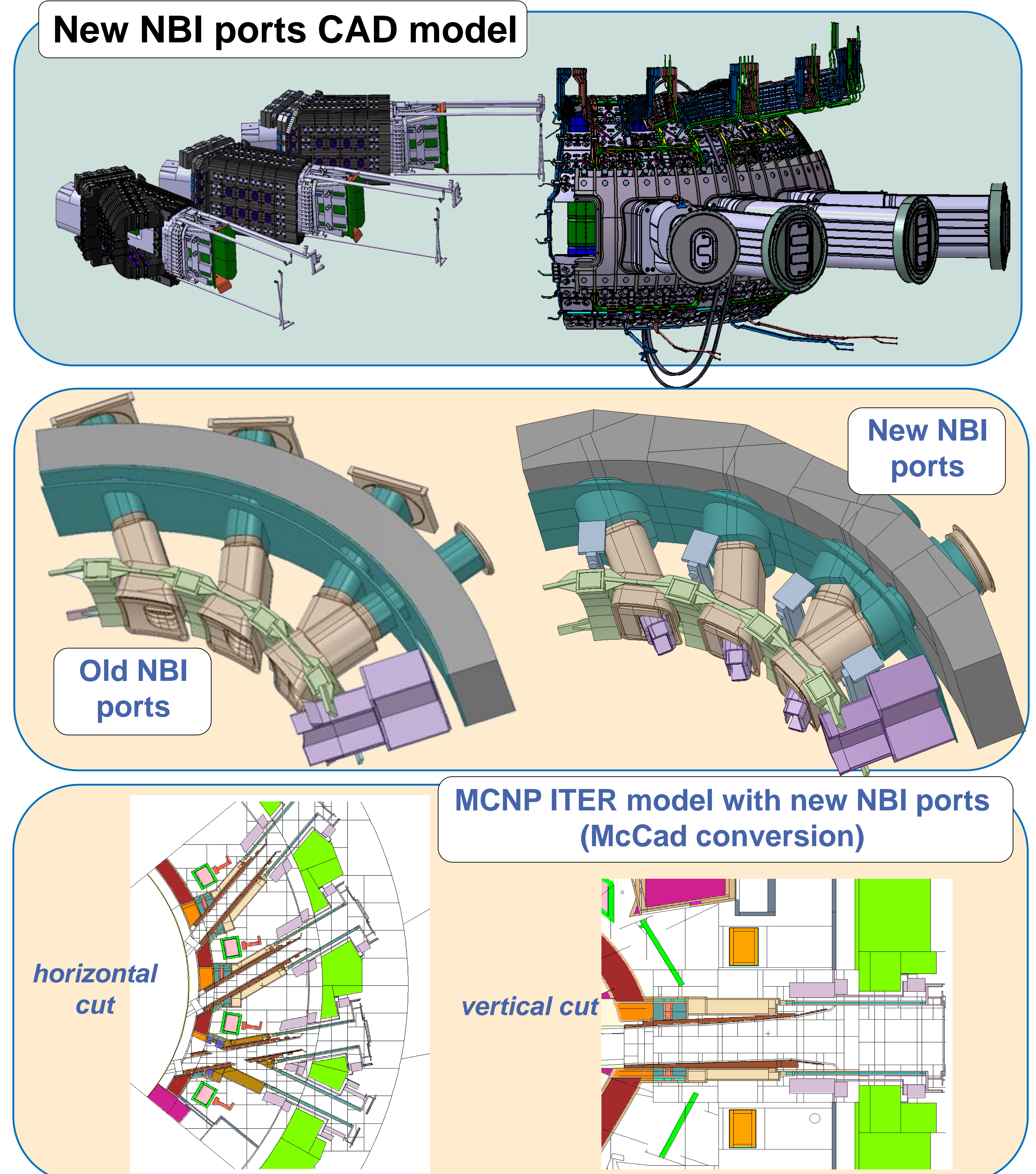

MCNP ITER model with new NBI ports (McCad conversion)

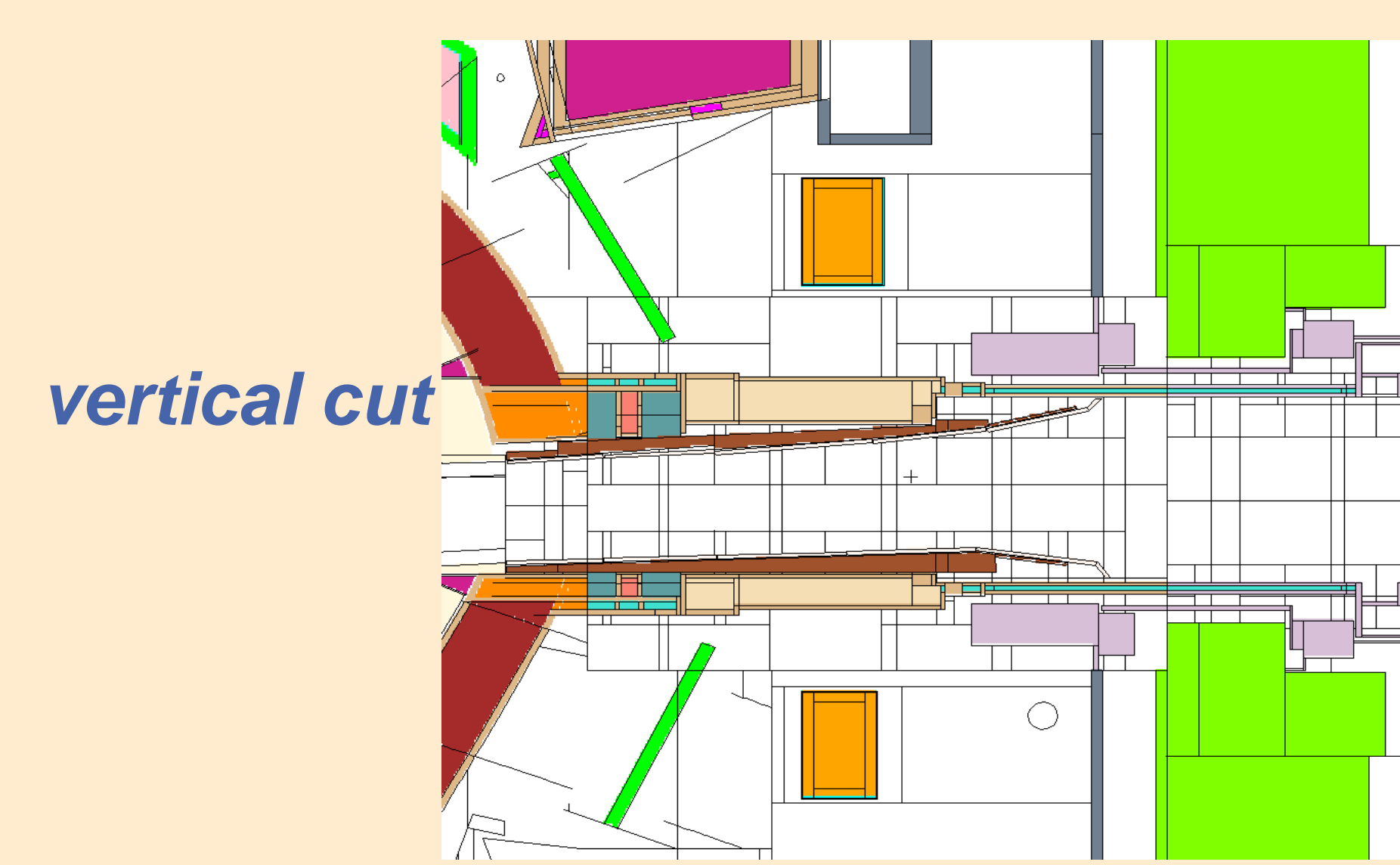

Power density distribution in vacuum vessel
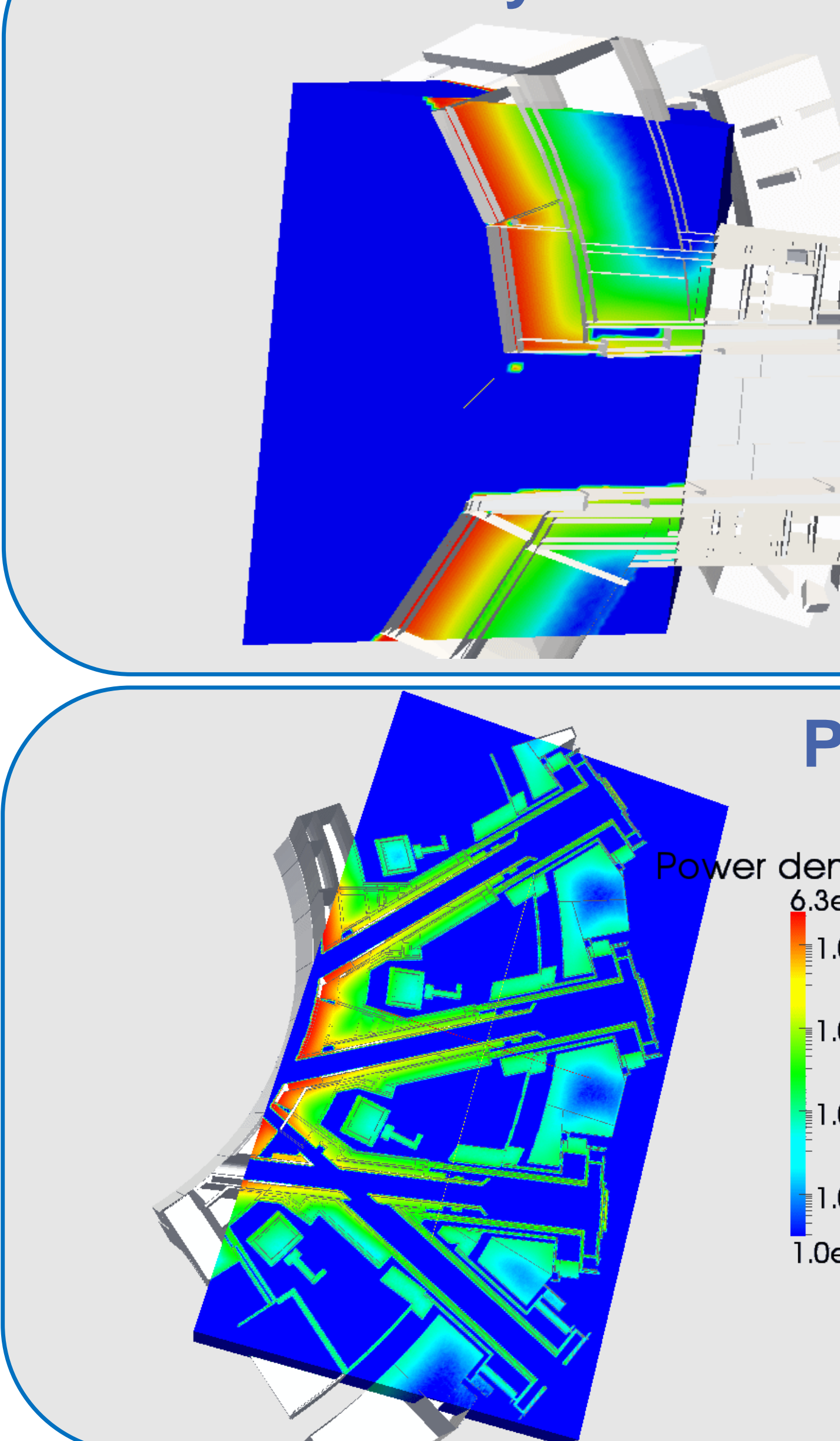

Power density distribution in all ducts
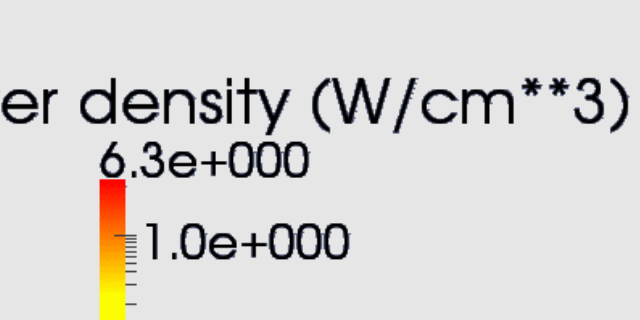

$1.00-002$

$1.00-004$

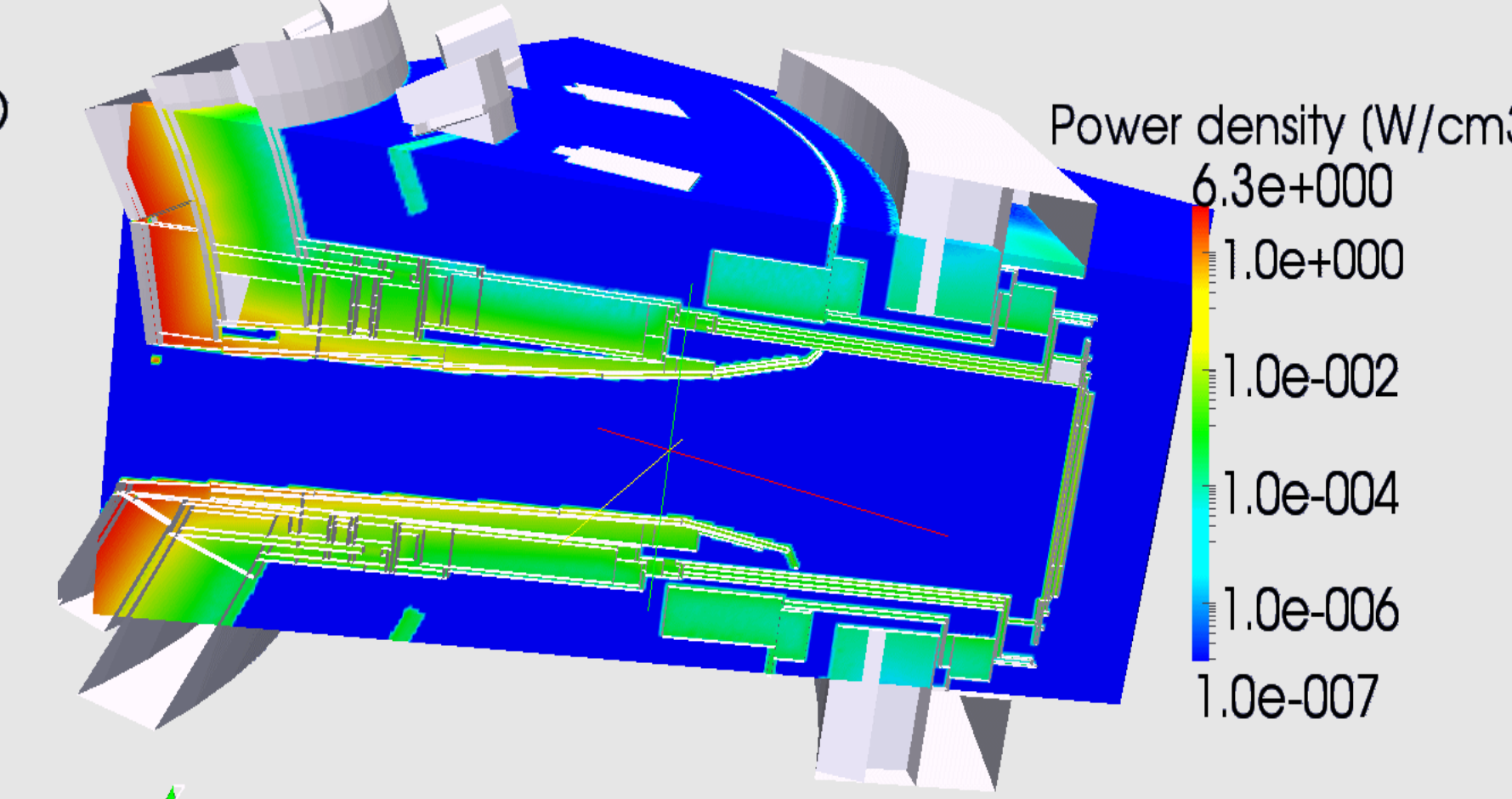

Dose and Neutron flux in insulator of theTF coils
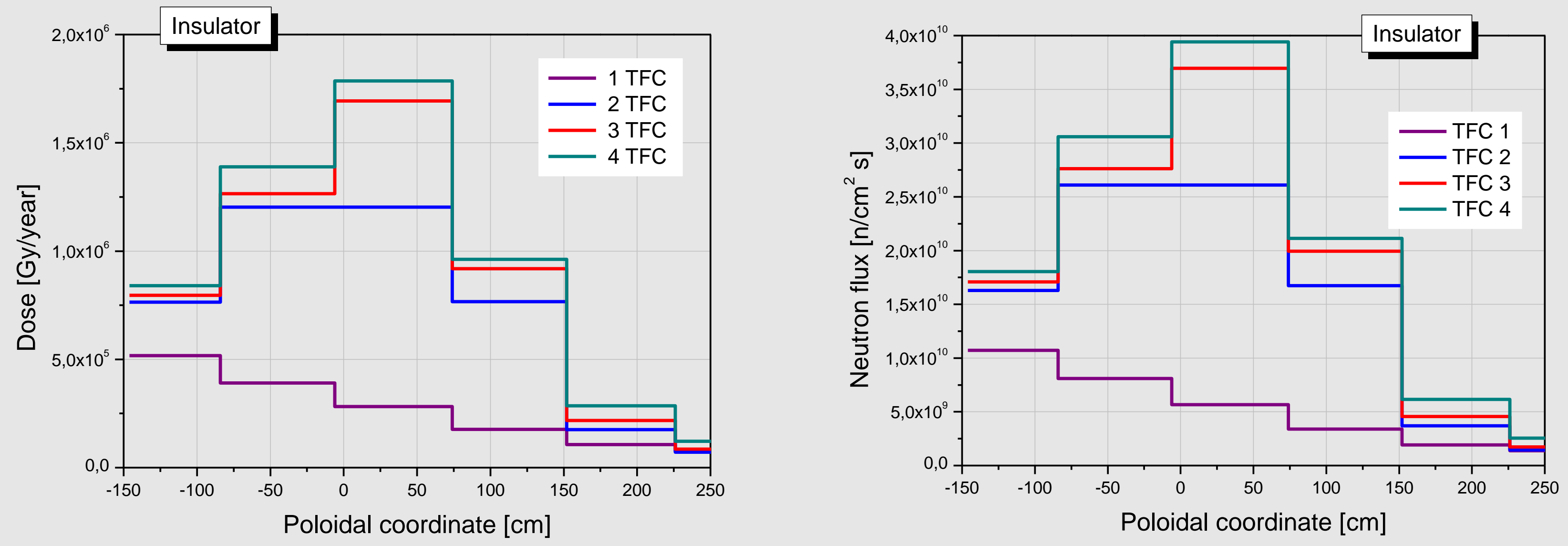

DPA and He-production in vacuum vessel
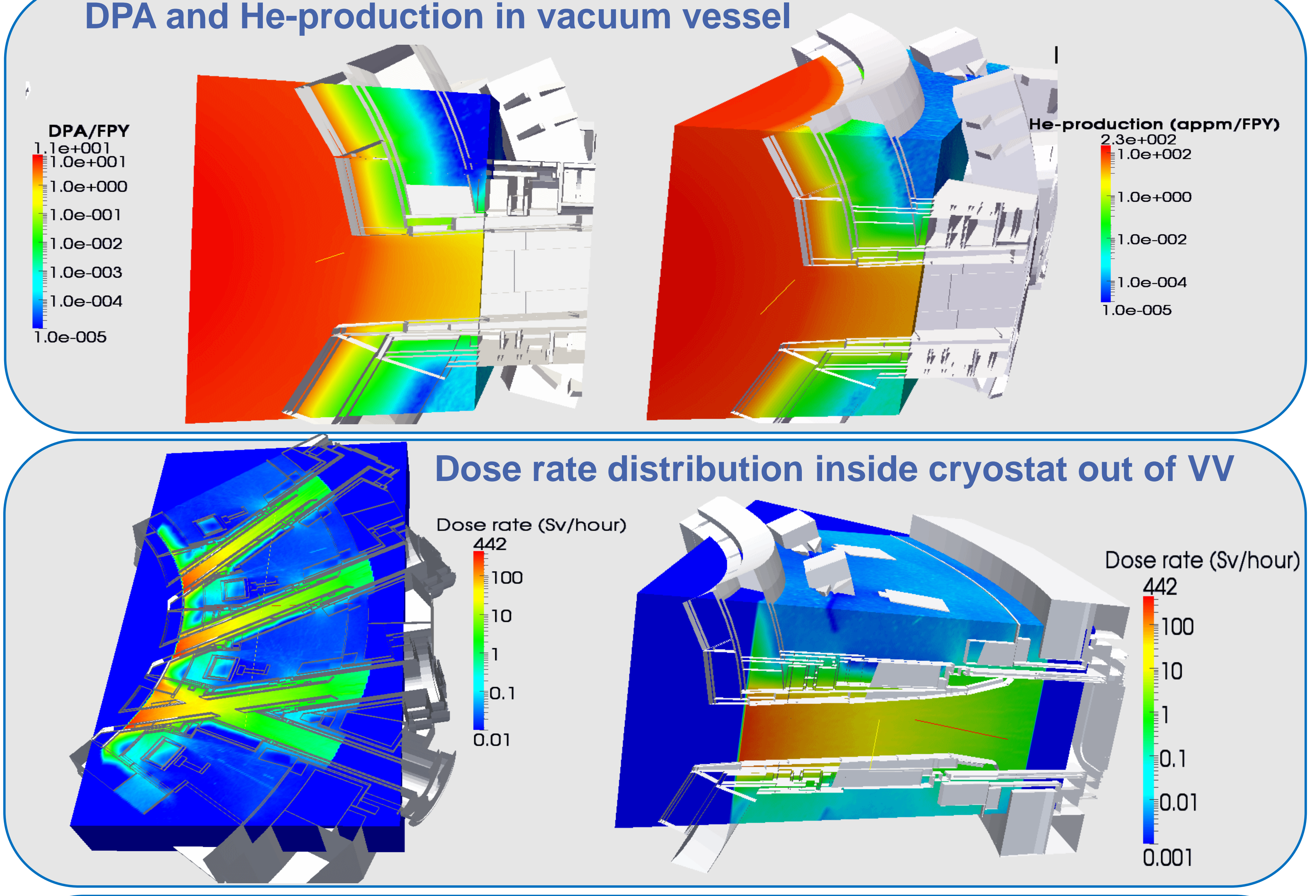

\section{CONCLUSIONS}

- NBI geometry models were generated by the conversion software McCad from engineering CAD models which had been adapted to the neutronic requirements.

A high quality, detailed MCNP geometry model of ITER with the NBI ducts included was produced. - Spatial distributions were calculated for several nuclear responses: the neutron flux, the nuclear powe density, He- and DPA production rates.

The dose to the insulator of the TFC magnets was shown to be lower than the ITER design radiation limits. The same applies for the nuclear loads to the TFC magnets.

The decay gamma dose rates in the space between vacuum vessel and TF were obtained using the advanced R2Smesh-2.1 method.

The results demonstrate a quite reliable shielding performance of the NBI ports shields assumed in the ITER design. 